\title{
Awareness, Perceived Impact and Views of Malaysian Accountants on the AML/CFT Requirements
}

\author{
Normah Omar, Zuraidah Mohd-Sanusi, and Hendi Prabowo
}

\begin{abstract}
Understanding the important roles of accountants as one of the non-financial businesses and professions (DNFBPs) as listed by Financial Action Task Force (FATF) in curbing the money laundering and terrorism financing activities, we conducted a survey to assess the level of awareness and perceived impact of the Malaysian chartered accountants on the Anti-Money Laundering/Counterfeit Financing Terrorism (AML/CFT) requirements, as well as their views on the cost and benefits in implementing the AML/CFT requirements. A total of 100 questionnaires were distributed to Malaysian chartered accountants from various scopes of works in Malaysia. Out of those, a total of 90 usable responses were received, which represent an effective response of $90 \%$. The findings from this study would provides an important insights regarding the awareness of the accountants and understanding regarding the AML/CFT requirements and is useful to the Malaysian Institute of Accountants, academician and other researchers.
\end{abstract}

Index Terms-AML/CFT, awareness, benefits, DNFBPs, perceived impact.

\section{INTRODUCTION}

As far as practicing accountants are concerned, the key development has been the updating of the FATF Recommendations in 2000 to extend the scope of the recommended AML controls from the banking sector only to a much wider range of what are called DNFBPs. By virtue of this change, controls and responsibilities which were previously directed solely at the banking sector have been extended to cover accountants and auditors, tax advisors, lawyers, company formation agents, estate agents and many other categories of advisor and business [1].

The FATF have stated that lawyers, notaries, accountants and other professionals offering financial advice are the common elements in complex money laundering cases. This is because, in order to circumvent money laundering countermeasures which have been put in place, launderers have to develop more complex schemes [2].

A research in UK shows that accountancy firms are engaged in anti-social behaviour. Evidence is provided to show that in pursuit of higher profits firms have operated cartels, engaged in tax avoidance/evasion, bribery, corruption

Manuscript received September 1, 2013; revised November 15, 2013. This work was supported in part by the Fundamental Research Grant Scheme Malaysian Ministry of Education and Research Management Institute, Universiti Teknologi MARA. Special thanks to the Master of Forensic Accounting and Financial Criminology students at the Universiti Teknologi MARA who have assisted in the data collection.

N. Omar and Z. Mohd-Sanusi are with the Accounting Research Institute, Universiti Teknologi MARA, 40450 Shah Alam, Selangor, Malaysia (e-mail normah645@salam.uitm.edu.my,zuraidahms@salam.uitm.edu.my).

H. Prabowo is with the Faculty of Economics, Universitas Islam Indonesia, Yogyakarta 55283, Indonesia (e-mail: hendi_prabowo@yahoo.com). and money laundering [3].

Other than Malaysia, around the globe, there at least, $90 \%$ of the FATF members were rated "PC" or "NC" with the AML/CFT requirements pertaining of DNFBPs. This area was of notable weakness for both FATF members and Developing Member Countries [4]. There are five (5) designated non-financial businesses and professions (DNFBPs) as listed by Financial Action Task Force (FATF), which include casinos, real estate agents, dealers in precious metals, dealers in precious stones, lawyers, notaries, other independent legal professionals and accountant, and trust and company service providers (MENAFATF, 2008).

The objective of the research is to (i) to explore and analyze the level of awareness regarding FATF recommendation on DNFBPs and perceived impact of DNFBPs of their responsibilities as reporting institutions; specifically on accountants, (ii) to identify the effectiveness, cost and benefits of AML/CFT requirement from accountants point of view.

\section{LITERATURE REVIEW}

\section{A. FATF 40+9 Recommendation Related to DFNBPs}

Up to 2012, FATF used this recommendation to assess the compliance level of countries. The last mutual evaluation report (MER) on Malaysia was in 2007. Under this recommendation [5] there are four recommendations related to DNFBPs which are Recommendation 12, 16, 24 and 25. Under Recommendation 12, the customer due diligence (CDD) and record-keeping requirements set out in Recommendations 5, 6, and 8 to 11 are apply to DNFBPs in situations stated in the recommendations.

As for Recommendation 16 which is related to suspicious transactions reporting (STR), the requirements set out in Recommendations 13 to 15 , and 21 are apply to all DNFBPs, subject to the qualifications stated in the recommendations. Recommendation 24 stated that DNFBPs should be subject to regulatory and supervisory measures as set out in the recommendations. Under Recommendation 25 the competent authorities should establish guidelines, and provide feedback which will assist financial institutions and DNFBPs in applying national measures to combat money laundering and terrorist financing, and in particular, in detecting and reporting suspicious transactions.

\section{B. Malaysia Third Mutual Evaluation Report}

Malaysia third Mutual Evaluation Report on 2007 shows that Malaysia partially compliance (PC) for Recommendation 12, 16 and 24. Otherwise, Malaysia had fulfilled requirement under Recommendation 25 with largely compliance (LC) [6]. For the next evaluation, by 2014, 
Malaysia is expected on 2014 to achive at least largely compliance (LC) for all recommendations related to DNFBPs. In order to achieve this goal, DNFBPs must follow all the guidelines for reporting institutions provided in AMLATFA 2001 and AML/CFT requirements.

Malaysia 4th Mutual Evaluation will be conducted on 2014. In order to fulfill the partially compliance (PC) to largely compliance on the DNFBPs recommendation, DNFBPs, especially the accountants are required to fulfill the AML/CFT requirement. As of now, there is still lack of study on the level of awareness among DNFBPs as related to their responsibilities on money laundering reporting. Does Malaysian accountants aware about the AML/CFT requirement especially regarding DNFBPs and perceived impact of DNFBPs of their responsibilities as reporting institution. How effective on the cost and benefit of AML/CFT requirement?

This paper fills a void in research in this area by looking at the level awareness among accountants in Malaysia as one of the designated non-financial professions.

\section{METHODOLOGIES}

\section{A. Research Design}

This research is a quantitative research as the data analysis procedure generates numerical data. Quantitative research is a methodology that seeks to quantify the data, typically, applies some form of statistical analysis [7]. The findings of quantitative research can be treated as conclusive and can be used to recommend a final course of action. In order to provide an explanatory research, the data generated are used to establish the relationship between the awareness, perceived impact, and views of Malaysian Accountants on the AML/CFT requirements.

\section{B. Sampling Design}

The target population for this research project is members of the Malaysian Institute of Accountants (MIA). The rationale for selecting members of the MIA as target population because it include one of reporting institutions (RIs) that stated in Money Laundering and Anti Terrorism Financing Act (AMLATFA 2001). The Financial Action Task Force (FATF) has named this group as "Designated Non-Financial Business and Professionals (DNFBPs)". RIs are legally obliged to report suspicious transactions when they have reason to suspect that the transaction involves proceeds from unlawful activity.

The sample size selected using purposive under judgment sampling design. The final sample selected is approximately 100 peoples of MIA members. The respondents were selected based on their expertise as a professional body. The sample is considered sufficient based on rules of thumb for determining sample size [8]. Based on this rules, a sample size that is more than 30 and less than 500 are appropriate for most research.

\section{Questionnaire Design}

The questionnaire was designed as the main survey instrument for this study. The instrument elicits data on exploring the level of awareness and perceived impact of DNFBPs especially members of MIA for their responsibilities as one of RIs. The research also divulge on the effectiveness, cost and benefit of AML/CFT requirement from accountants point of view.

The questionnaire consists of four sections, which are Section A, Section B, Section C and Section D. In Section A, one (1) question was designed to capture the information about the respondents' scope of work such as buying and/or selling of immovable property, managing clients' money, securities or other property, and managing of accounts including savings and securities accounts. The objective in this section is to get demographic information on respondents that can be used in the current research.

Section B asked respondents' understanding regarding to the AML/CFT. This section consists of two (2) sub-sections which are awareness and perceived impact. The instrument under awareness was cover about familiarity of definition of Anti-Money Laundering and Anti-Terrorism Financing Act (AMLATFA) 2001, and AML/CFT Requirements such as report suspicious transaction, record keeping of their customers and, to verify and identify of customers. For the effect of AMLATFA Act 2001 towards the accountants and the organizations, it was covered under perceived impact subsection. In addition, from this section we are able to determine whether the accountants have undergone any training related to AML/CFT during their employment terms.

Meanwhile, Section C solicited the respondents' opinions or views on effectiveness, cost and benefits of AML/CFT Requirements. These questions were designed to capture relevant information on respondents about the money laundering in general, effectiveness of the Act, effectiveness measures to deter and detect money laundering. Respondents were instructed to indicate their opinion based on five (5) points Likert-scale, ranging from ' 1 ' (strongly disagree) to ' 5 ' (strongly agree). As for cost and benefits of AML/CFT Requirement, it also used five (5) points Likert-scale, ranging from ' 1 ' (very low) to ' 5 ' (very high).

Finally, Section D provided questions solicited the respondents' demographic information such as gender, age group, academic qualification and job position.

\section{Data Collection}

The research instrument was pre-tested on five (5) MIA members working in the Klang Valley area before actual distribution of the questionnaire. The pilot test conducted is adequate as previous research hypothesized that sample for pre-test should be in a range that is more than five individuals and not more than 30 [9]. The respondents were asked to complete the questionnaires and provide appropriates comments regarding the questionnaires given. Among the responses given, the numbering structure of the questionnaires was not in sequence and there was a number of typing errors. The suggestion in the questionnaire should provide open ended comment section to enable respondents to express their own opinions and ideas. 100 questionnaires were distributed to MIA members who involved in various specific works randomly, where 90 usable responses were received. Once the respondents have completed the questionnaires, they were directly collected and further analyzed.

\section{RESEARCH FINDINGS}

The research findings are presented into three sub-sections. 
Sub-section 1 elaborates on the descriptive analysis of the survey. Sub-section 2 and 3 provide related data analysis categorized into the two research objectives.

\section{A. Descriptive Analysis}

The answered questionnaires collected from respondents were constructing as per Table I. This table summarizes the descriptive analysis of the study. In this study, there are about 100 sets of questionnaires and from that only 90 sets were returned. The questionnaires that were returned back by respondents could be used as a sample data because all questionnaires were completed. These 90 usable responses are represented as $90 \%$ of response rate.

TABLE I: DEMOGRAPHIC INFORMATION

\begin{tabular}{|c|c|c|c|}
\hline \multirow{2}{*}{ Description } & & \multicolumn{2}{|c|}{ Total } \\
\hline & & $\mathrm{N}=90$ & Percentage \\
\hline \multirow[t]{2}{*}{ Gender } & Male & 41 & 46 \\
\hline & Female & 49 & 54 \\
\hline \multirow[t]{4}{*}{ Age } & 21 to 30 years old & 31 & 35 \\
\hline & 31 to 40 years old & 46 & 51 \\
\hline & 41 to 50 years old & 11 & 12 \\
\hline & Above 50 years old & 2 & 2 \\
\hline \multirow[t]{7}{*}{ Qualification } & Professional & 15 & 17 \\
\hline & $\begin{array}{l}\text { Bachelor Degree } \\
\text { Professional }\end{array}$ & 12 & 13 \\
\hline & $\begin{array}{l}\text { Bachelor Degree + Master } \\
\text { Degree }\end{array}$ & 8 & 9 \\
\hline & $\begin{array}{l}\text { Bachelor Degree + Master } \\
\text { Degree + Professional }\end{array}$ & 2 & 2 \\
\hline & $\begin{array}{l}\text { Master Degree }+\mathrm{PhD}+ \\
\text { Professional }\end{array}$ & 1 & 1 \\
\hline & $\begin{array}{l}\text { Master Degree } \\
\text { Professional }\end{array}$ & 2 & 2 \\
\hline & Bachelor Degree & 50 & 56 \\
\hline \multirow[t]{5}{*}{ Experiences } & Below 5 years & 28 & 31 \\
\hline & 6 to 10 years & 21 & 23 \\
\hline & 11 to 15 years & 24 & 27 \\
\hline & 16 to 20 years & 10 & 11 \\
\hline & Above 20 years & 7 & 8 \\
\hline \multirow[t]{3}{*}{ Position } & Top Management & 16 & 18 \\
\hline & Middle & 19 & 21 \\
\hline & Executive & 55 & 61 \\
\hline \multirow[t]{3}{*}{$\begin{array}{l}\text { No. of } \\
\text { Employees }\end{array}$} & Below 100 & 47 & 52 \\
\hline & 100 to 1000 & 19 & 21 \\
\hline & Above 1000 & 24 & 27 \\
\hline
\end{tabular}

In general, 54\% (49/90) of respondents are female and $46 \%$ (41/90) of respondents are male. Around 51\% (46/90) of respondents are in the range of age between 31 to 40 years old. Meanwhile, 35\% (31/90) and 12\% (11/90) of respondents are in the range of age between 21 to 30 years old and 41 to 50 years old consecutively. The remaining respondents are in the range of age group above 50 years old which represent only $2 \%$ (2/90) of sample population.

Out of 90 respondents, 56\% (50/90) are Bachelor Degree; $17 \%$ (15/90) are Professional, 13\% (12/90) are Bachelor Degree and Professional; 9\% (8/90) are Bachelor Degree and Master Degree; 2\% (2/90) are Bachelor Degree, Master Degree, and Professional; 2\% (2/90) are Master Degree and Professional; and while only 1\% (1/90) are Master Degree, Professional, and PhD.

Meanwhile, for the length of working experiences, the majority of the respondents which are about $31 \%(28 / 90)$ have below five years of experiences, $27 \%$ (24/90) have 11 to 15 years of experiences, $23 \%$ (21/90) have 6 to 10 years of experiences, $11 \%(10 / 90)$ have 16 to 20 years of experiences, and $8 \%(7 / 90)$ have above than 20 years of experiences. Moreover, based on Table I, the percentage of respondents that have position in top management are $18 \%$ (16/90), $21 \%$ $(19 / 90)$ are in middle position, and the rest was in executive position which constitute of $61 \%$ of respondent (55/90).

Notably, $52 \%$ of 90 (47/90) respondents are from organizations that have below 100 of employees and $27 \%$ (24/90) of respondents are from organizations that have more than 1000 employees. The remainder of 21\% (19/90) of respondents are from organizations that have employees in the range of 100-1000 employees.

\section{1) Objective 1}

To explore and analyze the level of awareness regarding FATF recommendation on DNFBPs and perceived impact of DNFBPs of their responsibilities as reporting institutions; specifically on accountants.

- Awareness

The respondents were asked on the awareness of the AML/CFT amongst them and within the organizations which include the definition, the AMLATFA Act and the AML/CFT requirements. The 18 AML/CFT's awareness was ranked by using SPSS from the most strongly aware to the strongly unaware based on the mean score of the existence in the organizations.

The items that were answered by the respondents were ranked according to the section A2 of awareness on AMLATFA Act. There were four (4) items in the awareness on AMLATFA Act. Based on the result, the first rank is Awareness 3 that give mean score of 3.70. Awareness 3 is about the concept of money laundering and terrorism financing. The second rank is Awareness4 that give mean score of 3.44 and it is about Malaysia's enforcement agencies which are actively investigating money laundering and financial terrorism crime.

TABLE II: THE AMLATFA ACT

\begin{tabular}{lcc}
\hline \hline & Mean & Std. Deviation \\
\hline Awareness3 & 3.70 & .905 \\
Awareness4 & 3.44 & .901 \\
Awareness6 & 3.41 & 1.016 \\
Awareness5 & 3.08 & 1.104 \\
\hline \hline
\end{tabular}

It is then followed by Awareness6 on the third rank. (See Table II) The mean score is 3.41 and the awareness is about the requirements of AMLATFA Act 2001. On the other hand, the awareness on the responsibility of the reporting institutions (Awareness5) falls on the fourth rank with a mean score of 3.08 .

Based on the above finding for section A3, it point out about the awareness on AML/CFT requirements. Thus, the study ranked the items in the questionnaire that was answered by the respondents. There were twelve (12) items on the awareness of AML/CFT requirements. Based on the result, the first rank is Awareness8 that give means score of 3.91, which is about RIs that are required to keep records of customers for at least 6 years and should be stored securely in a form that is retrievable in timely manner upon request. 
TABLE III: THE AML/CFT REQUIREMENTS

\begin{tabular}{lcc}
\hline \hline & Mean & Std. Deviation \\
\hline Awareness8 & 3.91 & 1.002 \\
Awareness7 & 3.84 & 1.059 \\
Awareness9 & 3.78 & 1.003 \\
Awareness11 & 3.66 & .985 \\
Awareness10 & 3.60 & 1.026 \\
Awareness13 & 3.59 & .970 \\
Awareness12 & 3.49 & 1.008 \\
Awareness14 & 3.17 & 1.164 \\
Awareness15 & 3.08 & 1.201 \\
Awareness18 & 3.07 & 1.149 \\
Awareness17 & 3.00 & 1.039 \\
Awareness16 & 2.86 & 1.076 \\
\hline \hline
\end{tabular}

Followed by the second rank is Awareness7 with a mean score of 3.84. See Table III, Awareness7 is about a mandatory obligation to report suspicious transactions when RIs have reason to suspect that the transaction involves proceeds from an unlawful activity. Meanwhile, Awareness 9 was on the third rank with a mean score of 3.78 and it is RIs which are required to verify, by reliable means, the identity of customers and beneficial owners.

Subsequently, the awareness on the needs of RIs to develop and put in place effective internal programmes, policies, procedures and controls to deter and detect in accordance to AML/CFT-related legislation(Awareness11) fall under the forth rank with a mean score of 3.66. It was then followed by the fifth rank (Awareness10). With a mean score of 3.60, Awareness 10 is about RIs may use risk-based approach in setting out the procedures for effective customer/beneficiary identification and verification.

Given a mean score of 3.59, Awareness 13 which is about RI's compliance programme should include on-going employee training programme to ensure employees are fully aware of their obligations fall under the sixth rank. On the seventh rank is Awareness12 with a mean score of 3.49. RIs are required to appoint a compliance officer who will be in charge of applying internal AML/CFT procedures.

The eight ranks is Awareness 14 that give means score 3.17 and it is about reporting of suspicious transactions to the financial intelligence unit (FIU) in Bank Negara Malaysia is performed through the submission of information in the prescribed Suspicious Transactions Report (STR) form or through the Financial Intelligence System.

The ninth rank is awareness 15 that give means score 3.08 which is RIs need to check and match customers' names against the United Nations Consolidated List published or the name list as specified by the Minister of Home Affairs. The tenth rank is awareness 18 that give means score 3.07 which is about tipping off to the customer about a STR is an offence under the AMLATFA Act.

Then, the eleventh rank is awareness 17 that give means score 3.00 and indicates about the compliance officer need to submit a STR to the FIU as soon as possible, thereafter continue to monitor the activities of the reported account or person. The last rank is awareness 16 that give means score 2.86 where the completed STR must be submitted to FIU.

Actually, the qualification of a member does not necessarily indicate that they understand and aware on the AMLATFA Act and requirements. Due to the less of awareness campaign by the law enforcement towards the DNFBPs in Malaysia, the MIA members are lack of awareness especially in the submission of the completion of Suspicious Transaction Report (STR) to Financial Investigation Unit (FIU).

- Perceived impact

As referred to the questionnaires, the perceived impact is under Section A which is on Part A3 whereby it consists of five questions. This section indicates the perceived impact towards the accountants as well as to their organization. In addition, this section also determines the availability of resources. There are two items on the impacts and it were ranked from very unaffected to very affected. Impact1 is to measure to what extent the AMLATFA Act 2001 that was enhanced in 2004 will affect the accountants itself and the Impact 2 will measure to what extent the AMLATFA Act 2001 will affect their organization.

On the other hand, Impact10 will measure whether the professional body provides available resources to the accountant itself regarding the AML/CFT. Meanwhile, the availability of resources was ranked accordingly from little resource availability to excellent resource availability. However, the respondents were able to choose more than one option regarding the types of training that they have attended.

TABLE IV: PERCEIVED IMPACT

\begin{tabular}{|c|c|c|c|c|}
\hline & & Impact1 & Impact2 & Impact 10 \\
\hline Mean & & 3.02 & 3.18 & 3.36 \\
\hline Median & & 3.00 & 3.00 & 3.00 \\
\hline Mode & & 4 & 3 & $3^{\mathrm{a}}$ \\
\hline Std. Deviation & & 1.10 & 1.05 & 1.00 \\
\hline Sum & & 272 & 286 & 279 \\
\hline \multirow[t]{3}{*}{ Percentiles } & 25 & 2.00 & 2.75 & 3.00 \\
\hline & 50 & 3.00 & 3.00 & 3.00 \\
\hline & 75 & 4.00 & 4.00 & 4.00 \\
\hline
\end{tabular}

Based on Table IV, in terms of the perceived impact, the result shows that the MIA members (Mean=3.02) was quite affected by AMLATFA Act 2001 as compared to the impact towards organization itself which are moderately affected (Mean=3.18). In addition, the resources regarding AML/CFT provided by professional bodies was moderately available with the mean computed was 3.36 .

TABLE V: AML/CFT TRAINING

\begin{tabular}{|c|c|c|}
\hline & Mean & Std. Deviation \\
\hline Accreditation programs & 1.99 & 0.105 \\
\hline Video/DVD & 1.99 & 0.105 \\
\hline Others & 1.98 & 0.148 \\
\hline Computer-Based-Training & 1.83 & 0.404 \\
\hline By providing written material & 1.83 & 0.375 \\
\hline Face-to-face training & 1.76 & 0.432 \\
\hline
\end{tabular}

Based on the above findings (See Table V), it specifies that most of the respondents had attended training on Accreditation programs and Video or DVD with a mean score of 1.99 and the standard deviation is 0.105 . Then, it followed by other types of training such as seminar whereby 
the mean score is 1.98 .

Moreover, training on computer based and based on providing written material shows the same value of mean score, which is 1.83 . In addition, the face-to-face training is show the lowest value of mean score, which is 1.76 .

\section{2) Objective 2: To identify the effectiveness, cost and benefit of AML/CFT requirement from accountants point of view.}

The respondents were asked on the topic of their views on costs and benefits of AML/CFT Requirement and 100 questionnaires were distributed to Malaysian chartered accountants from various scopes of works in Malaysia. About 17 questions have been asked and the questions consist of generally about money laundering, the effectiveness of AMLATFA and the effective measures to deter and detect money laundering.

TABLE VI: OPINION MONEY LAUNDERING IN GENERAL RANKING

\begin{tabular}{lcc}
\hline \hline & Mean & Std. Deviation \\
\hline View3 & 4.36 & .812 \\
View4 & 4.33 & .821 \\
View5 & 4.24 & .839 \\
View2 & 4.22 & .858 \\
View1 & 4.11 & .953 \\
\hline \hline
\end{tabular}

See Table VI, there were five (5) items in the opinion of money laundering in general. Based on the result, the first rank is View3 with a mean score of 4.36 and standard deviation 0.812 . To achieve the goal of combating money laundering activities, it requires commitment from the top management of the organization.

The second rank is View4 that give mean score of 4.33 and standard deviation 0.821 . The view is on whether it is essential for all the reporting institutions as well as the enforcement agencies to work together in combating money laundering and terrorism financing. On the third rank is View5 that give mean score of 4.24 and standard deviation 0.839 . The question was asked to gather the view of the members on the need of the professional body to work or participate actively in building human capital building program or specialist as an effort to mitigate money laundering and terrorism financing.

With a mean score of 4.22 and standard deviation 0.858 , the view of respondents on the fact that money laundering activities if not mitigated would lead to disastrous consequences to a country's economy (View5) is on the forth rank. The fifth rank is belonging to View1. The respondents were asked to give their opinions on whether money laundering activities is a great concern in the present time or not.

From this result, we can conclude that, the most agreed opinion for money laundering in general by the respondent is the goal to combat money laundering activities requires commitment from the top management of the organization.

For opinion or views on effectiveness of the AMLATFA in section B2, based on the result, the opinions were ranked accordingly. There were five (5) items in the opinion or views on effectiveness of the AMLATFA. Based on the result, the first rank is View10 that give means score of 4.14 and the standard deviation is 0.758 . According to the respondents, there should be more information sharing between the reporting institutions and enforcement agencies.

On the other hand, the second rank is View9. With mean score of 4.10 and standard deviation is 0.735 , the respondents were agreed that the government should enforce the law more to combat the anti-money laundering and anti-terrorism financing.

TABLE VII: EFFECTIVE ACT RANKING

\begin{tabular}{lcc}
\hline \hline & Mean & Std. Deviation \\
\hline View10 & 4.14 & .758 \\
View9 & 4.10 & .735 \\
View8 & 3.93 & .934 \\
View7 & 3.71 & .997 \\
View6 & 3.47 & .902 \\
\hline \hline
\end{tabular}

Meanwhile, see Table VII, View8 which is about whether the government should pass more laws to combat the anti-money laundering and anti-terrorism financing fall under the third rank with a mean score of 3.93 and the standard deviation is 0.934 . On the forth rank is View7.

The respondents were asked on their opinion on the availability of good legislation about anti-money laundering and anti-terrorism financing but it is not completely enforced. The fifth rank that give mean score 3.47 and standard deviation 0.902, which is current legislation about anti-money laundering and anti-terrorism financing is sufficient to prevent money laundering and terrorism financing activities. From this result, the study can conclude that, the most agreed opinion or views on effectiveness of the AMLATFA by the respondents is there should be more information sharing between the reporting institutions and enforcement agencies.

TABLE VIII: EFFECTIVENESS MEASURES to DETER AND DeteCt MONEY LAUNDERING RANKING

\begin{tabular}{lcc}
\hline \hline & Mean & Std. Deviation \\
\hline View12 & 4.24 & .754 \\
View14 & 4.23 & .735 \\
View16 & 4.21 & .662 \\
View15 & 4.20 & .782 \\
View17 & 4.19 & .685 \\
View11 & 4.12 & .846 \\
View13 & 4.11 & .741 \\
\hline \hline
\end{tabular}

For opinion or views on effectiveness of AML/CFT requirements in $\mathrm{B} 3$ section, based on the result (See TAVBLE VIII), the opinions were rank accordingly. There were seven(7) items in the views on effective measures to deter and detect money laundering. Based on the result, the first rank is View12 that give mean score 4.24, where respondent agreed that enforcement action by the law enforcement authorities is an effective measure to deter money laundering. The second rank is View14 that give mean score 4.23, which indicate the strong compliance culture within an organization is an effective measure to detect money laundering.

Confidential reporting channel based on suspicious transaction report is an effective measure money laundering (View16) was in third ranked which provides mean score 4.21.The next ranking is respondents agreed on sharing of information between regulatory auhorities and the reporting 
institutitions, followed by severe punishment or penalty to the organization, and create AML/CFT awareness program were an effective measure to deter and detect money laundering. From this result, this study can conclude that, the most agreed opinion is on enforcement action by the law enforcement authorities is an effective measure to deter money laundering.

\begin{tabular}{lcc}
\multicolumn{3}{c}{ TABLE IX: Cost OF AML/CFT } \\
\hline \hline Mean & 3.10 \\
\hline Median & 3.00 \\
Mode & 3 \\
Std. Deviation & & .918 \\
Sum & & 276 \\
\hline Percentiles & & 2.50 \\
& 25 & 3.00 \\
& 50 & 4.00 \\
\hline \hline
\end{tabular}

See Table IX, concerning the cost of implementing AML/CFT Requirements for the next three years, most of respondents believe that the cost will be increased by less than $20 \%$ (Mean=3.10) for their organization.

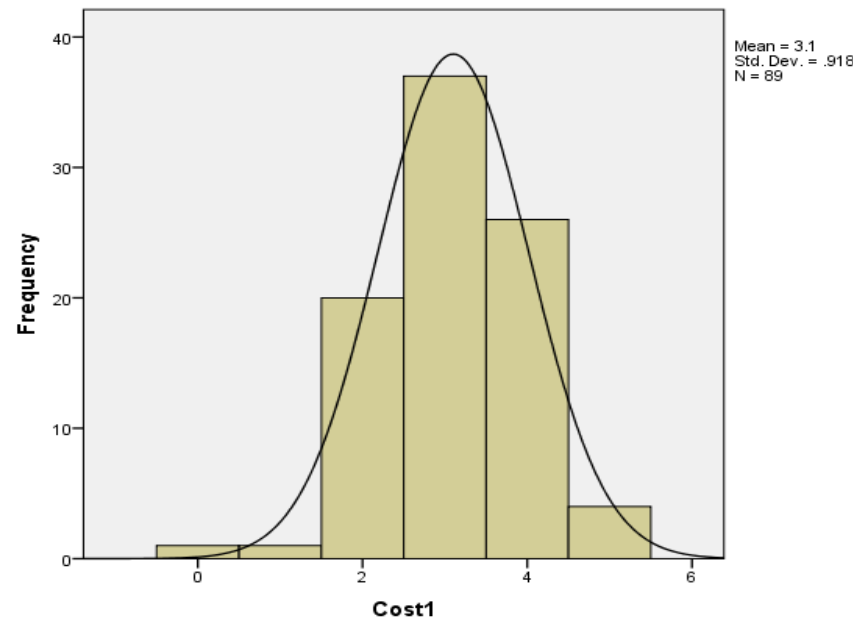

Fig. 1. Level of benefit ranking.

TABLE X: LEVEL OF BENEFIT RANKING

\begin{tabular}{lcc} 
& TABLE X: LEVEL OF BENEFIT RANKING \\
\hline \hline & Mean & Std. Deviation \\
\hline Benefit5 & 3.99 & .772 \\
Benefit2 & 3.96 & .748 \\
Benefit6 & 3.89 & .917 \\
Benefit7 & 3.88 & .864 \\
Benefit4 & 3.84 & .763 \\
Benefit3 & 3.79 & .918 \\
Benefit8 & 2.51 & .623 \\
\hline \hline
\end{tabular}

In section B4(2), see Fig. 1, which is the level of benefit for the organization for the next three (3) years, the study measure of the items in this questionnaire by very low level of benefit to very high level of benefit. Based on the result, the study ranked the item in descending ranking from very high level to lower level of benefit for organization. See Table $\mathrm{X}$, for the first rank is Benefit5 that give mean score 3.99 and standard deviation 0.772 which is effective at combating money laundering, followed by second rank, Benefit2 that give mean score 3.96 and standard deviation
0.748 which is represent good business practice.

For the third rank is Benefit6 that give mean score 3.89 and standard deviation 0.917 , which is reduce fraud cases and followed by better customer knowledge in fourth rank that give mean score 3.88 and standard deviation 0.864. Fifth rank is Benefit4 that give mean score 3.84 and standard deviation 0.763 , is effective at combating money laundering and for sixth rank is Benefit3 that give mean score 3.79 and standard deviation 0.918 which is avoid (protect) sanctions from authorities. The last rank is Benefit8 that give mean score 2.51 and standard deviation 0.623 which is others. From this result, the study can conclude that, the very high level of benefit is Benefit5, which is effective at combating money laundering.

\section{CONCLUSION}

The main objective of this study is to explore and analyze the level of awareness and perceived impact of Anti Money Laundering Act/Counterfeit Financing Terrorism (AML/CFT) requirements on Malaysian accountants of their responsibilities as reporting institutions. Apart from that, this study also attempts to identify the effectiveness, cost and benefit of AML/CFT requirement.

In term of awareness, results from the analysis show that most of the respondents are aware on the requirement for RIs to keep records of customers for at least 6 years and should be stored securely in a form that is retrievable in timely manner upon request and it was ranked first. It was then followed by awareness on mandatory obligation to report suspicious transactions when RIs have reason to suspect that the transaction involves proceeds from an unlawful activity and RIs are required to verify, by reliable means, the identity of customers and beneficial owners. Meanwhile, the impact of AML/CFT leads to awareness of RIs by accreditation programs, video or DVD, and others such as seminar and training.

In regards of effectiveness of the act, most of accountants agreed that there should be more information sharing between the reporting institutions and the most effective measure to deter and detect money laundering is through enforcement action by the law enforcement authorities. It is also expected that the cost of implementing the AML/CFT requirements will increase by less than $20 \%$ in the next three years of implementations. Furthermore, the accountants also agreed that by implementing the AML/CFT requirements will represent good business practice as well as reduce the fraud cases.

Based on this survey of awareness, perceived impact and views of Malaysian accountants on the AML/CFT requirements, this study shows effective at combating money laundering, good business practice and reduces fraud cases are among the benefit that will be gain once the organizations implement AML/CFT requirements in their organizations.

\section{Limitation of the Study and Recommendations for Future Research}

The result of this study might not have been as robust as they ideally should be as study only focused on a small number of respondents (100 questionnaires). Furthermore, the questionnaires have been distributed within the peak 
period for accountants and they could not give full commitment and cooperate towards the questionnaires. Other than that, there is only short length of period to conduct this survey, which from $4^{\text {th }}$ June 2013 till $18^{\text {th }}$ July 2013.

It is recommended for MIA to take proactive actions to ensure the accountants not only aware about the AML/CFT requirements, but also understand their responsibilities as the reporting institutions. More training or courses on AML/CFT should be conducted, emphasizing on the responsibilities of the accountants as one of DNFBPs.

On the other hand, to ensure that the accountants are realize about this responsibility, the government should establish an association where all the accountants should be registered as the DNFBPs, regardless the accountants are registered MIA members or otherwise.

In addition, more campaigns on AML/CFT need to be organized by government in order to spread the awareness on the AML/CFT. This will not only benefit the accountants but also the public. To increase the accountants' level of awareness on their responsibility, the government should establish an association where all the accountants should be registered as the DNFBPs, regardless the accountants registered as MIA members or otherwise.

Lastly, the organization is recommended to provide and organized more trainings to its employees. This can be implemented by conducting on-going employee training programme, or send the employees to participate in any courses related to AML/CFT organized by MIA.

\section{REFERENCES}

[1] ACCA, Accountants and Money Laundering - A Brief Guide for UK Practising Firms, ACCA UK, London, 2008.

[2] R. E. Bell, "An introductory who's who for money laundering investigators," Journal of Money Laundering Control, vol. 5, no. 4, pp. 287-295, 2002
[3] P. Sikka, "Enterprise culture and accountancy firms: New masters of the universe," Accounting, Auditing \& Accountability Journal, vol. 21 no. 2, pp. 268-295, 2008

[4] N. Jensen and C. A. Png, "Implementation of the FATF 40+9 recommendations," Journal of Money Laundering Control, vol. 14, no. 2, pp. 110-120, 2010.

[5] FATF/OECD, FATF 40 Recommendations, FATF Standards, Financial Action Task Force, 2010.

[6] APG, APG Mutual Evaluation Report on Malaysia, 2007.

[7] N. K. Malhotra, Marketing Research: An Applied Orientation, 5th ed., Upper Saddle River, NJ: Prentice Hall, 2007.

[8] J. T. Roscoe, Fundamental Research Statistics for the Behavioral Sciences, 2nd ed., New York: Holt, Rinehart and Winston, 1975.

[9] J. F. J. Hair, A. H. Money, P. Samouel, and M. Page, Research Methods for Business, John Wiley and Sons, Inc, 2007.

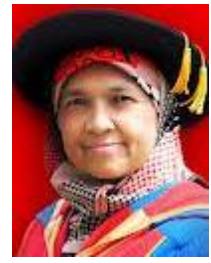

Normah Omar is currently the director of the Accounting Research Institute (ARI), Universiti Teknologi MARA. Her current research interest is in the area of forensic accounting and financial criminology. Recently ARI has been recognized as a national centre of excellence under the Ministry of Higher Education (HICoE). Her current research interests are in the areas of: Anti-Money Laundering \& Counter Financing of Terrorism (AML-CFT); Fraud Risk Indicators Corporate Integrity System; Fraud Prevention Mechanism and Islamic Microfinancing.

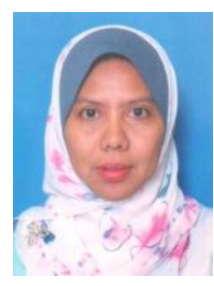

Madya Zuraidah Mohd Sanusi is currently the deputy director of the Accounting Research Institute (ARI), Universiti Teknologi MARA and lecturer of Faculty of Accountancy. Her current research interest is in the area of forensic accounting, financial criminology, auditing and corporate governance.

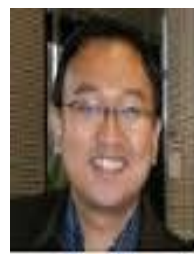

Hendi Yogi Prabowo is currently the director of Islamic University of Indonesia's Centre for Forensic Accounting Studies. His current research interest is in the area of forensic accounting and financial criminology. 